\title{
Physics 2.0
}

A degree of progress.

Dear Dean Pandaring,

As per our discussion last week, I agree that we need to undertake some measures to slow the decline of enrolments for the physics BA and BS. There is no escaping the hard numbers that you cited: the number of physics majors on campus has declined steadily for more than a decade. Falling enrolments are now endemic to the hard sciences, engineering and mathematics.

I understood, also, your injunction that we consider the interests of students. It remains my belief that it is the difficulty of the sciences that is discouraging majors and not, as you suggested, any failure of the sciences to be useful or even remunerative (I assume this is what you meant when you said the sciences had become "less accepting of the integrative task-directives of students' learning and personal growth goals"). Let me draw your attention to the fact that, with a degree in a hard science, a student typically finds a job immediately upon graduation that (1) he or she would not otherwise have been eligible to undertake without a BA or BS, and that (2) pays more money than alternative positions that are open to individuals with any degree or with no degree. Neither of these benefits can be claimed for the other degree programmes on campus.

Finally, I agree that the explosion of enrolment for the new degree of crime broadcasting is illustrative of the dynamic growth a university programme can have when it follows the latest trends in the interests of our students. Previously, such examples have not been very helpful to us because there simply was no way for us to teach physics without requiring mathematics, periodic homework and weekly work in the lab - the very endeavours that students are increasingly, as you said, "Voting against in the market of education choices". It has been especially difficult to compete in this market with the glamour of the Communications School, which has large make-up rooms, gilded stages, plasma televisions in each bathroom stall and classrooms with cappuccino bars. Our facilities have nothing to offer but liquid-nitrogen-cooled scientific instruments in poorly lit laboratories.

I am proud to say, however, that we have found a way to meet this challenge. I have developed a proposal that provides an exciting opportunity for our students, is sure to increase enrolments, and may help to preserve the Department of Physics from any further cutbacks.

I propose a new major in fictional physics, the study of the behaviour of virtual matter in a virtual world.

Given that our students now spend as many of their waking hours in virtual worlds as in the physical world, this degree has the potential to become one of the most popular on campus. A recent study of our undergraduates revealed that they spend an average of 47 hours per week immersed in a virtual gaming world (along with 84 hours sleeping, 32 hours in meals and miscellaneous recreation, 3 hours in class, 2 hours studying, and 1 hour in managing personal hygiene - please note that the additional hour each week is thought to arise because 1 hour of sleep or managing of personal hygiene occurs in class). A degree programme that rewards students with a BS for pursuing their recreation will be a winning market proposition.

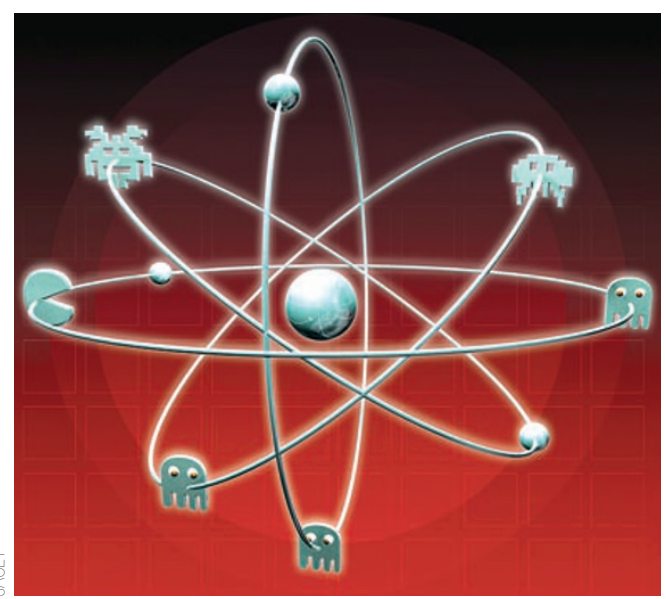

We have already prepared a number of courses for this major. They include FPHY 200 and 201: Virtual Ballistics I and II; FPHY 285: Space Travel in NonRelativistic Worlds; FPHY 310: Fluid Dynamics of Instantaneous Weather; FPHY 411: Symmetry and Asymmetry of Fake Spaces; FPHY 459: Basic Thermodynamics of Fictitious Explosions; and FPHY 211: Intensive PseudoExperimental Methods (a lab that requires 12 hours of gaming a week). Best of all, these courses can be taken online. This means we can admit students located anywhere in the world, that teaching and grading can be automated, and that the programme will require no additional facilities spending by the university.

There need be no concern about encroaching upon the subject matter of the Department of Information Management. I have talked with their chair, and he assures me that, since they changed their name from Computer Science to Information Management, and fired all of their theorists, they no longer have an interest in the study of algorithms, complexity, artificial intelligence, simulations or related matters. Furthermore, they are not seeking new majors, as they already have more students than they can possibly serve on the waiting lists for their courses IMA 285: Connecting Your Computer Peripherals and IMA 310: Music and Movies Downloading.

In addition to the potential gain to our department in increased enrolment, this new degree could offer unique benefits to students. Graduates with a BS in fictional physics could pursue exciting careers in online gaming. Although competition for jobs writing and testing virtual worlds for games is extremely stiff — with 285 applicants per job, on industry average - this offers a far better prospect for employment than the seven most popular majors on campus: Crime Broadcasting (where majors outnumber mean relevant job openings each year by a ratio of 594 to 1), Serial Killer Forensic Science Investigations (658 to 1 ), the joint major in Parapsychological and Cryptozoological Counselling (993 to 1), Television Game Theory (1,012 to 1$)$ and Extreme Sports Travel and Resort Management (2,865 to 1$)$.

It is thus my belief that the new major in fictional physics will be accepting of the integrative task-directives of students' learning and personal growth goals.

Let us arrange a meeting next week to discuss this important opportunity.

Dr Talia Trounced

Chair, Department of Physics.

\section{Craig DeLancey}

Along with writing hard SF stories, Craig DeLancey teaches philosophy at the State University of New York and is the author of Passionate Engines: What Emotions Reveal about the Mind and Artificial Intelligence (Oxford University Press). 